Pesq. Vet. Bras. 37(11):1253-1260, novembro 2017 DOI: $10.1590 / \mathrm{S} 0100-736 \mathrm{X} 2017001100010$

\title{
Genotyping and antimicrobial resistance in Escherichia coli from pig carcasses ${ }^{1}$
}

\begin{abstract}
Caroline Pissetti ${ }^{2}$, Gabriela Orosco Werlang ${ }^{2}$, Jalusa Deon $\mathrm{Kich}^{3}$ and Marisa Cardoso ${ }^{2 *}$
ABSTRACT.- Pissetti C., Werlang G.O., Kich J.D. \& Cardoso M. 2017. Genotyping and antimicrobial resistance in Escherichia coli from pig carcasses. Pesquisa Veterinária Brasileira 37(11):1253-1260. Departamento de Medicina Veterinária Preventiva, Faculdade de Veterinária, Universidade Federal do Rio Grande do Sul, Av. Bento Gonçalves 9090, Porto Alegre, RS 91540-000, Brazil. E-mail: mcardoso@ufrgs.br

The increasing antimicrobial resistance observed worldwide in bacteria isolated from human and animals is a matter of extreme concern and has led to the monitoring of antimicrobial resistance in pathogenic and commensal bacteria. The aim of this study was to evaluate the antimicrobial resistance profile of Escherichia coli isolated from pig carcasses and to assess the occurrence of relevant resistance genes. A total of $319 \mathrm{E}$. coli isolates were tested for antimicrobial susceptibility against different antimicrobial agents. Moreover, the presence of extended-spectrum $\beta$-lactamase (ESBL) and inducible ampC- $\beta$-lactamase producers was investigated. Eighteen multi-resistant strains were chosen for resistance gene detection and PFGE characterization. The study showed that resistance to antimicrobials is widespread in E. coli isolated from pig carcasses, since $86.2 \%$ of the strains were resistant to at least one antimicrobial and $71.5 \%$ displayed multi-resistance profiles. No ampC-producing isolates were detected and only one ESBL-producing $E$. coli was identified. Genes strA $(\mathrm{n}=15)$, floR $(\mathrm{n}=14), \operatorname{aac}(3) \mathrm{IVa}(\mathrm{n}=13)$, tet $\mathrm{B}(\mathrm{n}=13)$, sul2 $(\mathrm{n}=12)$, tet $\mathrm{A}(\mathrm{n}=11), \operatorname{aph}(3)$ Ia $(\mathrm{n}=8)$ and $\operatorname{sul} 3(\mathrm{n}=5)$ were detected by PCR. PFGE analysis of these multi-resistant $E$. coli strains showed less than $80 \%$ similarity among them. We conclude that antimicrobial multi-resistant E. coli strains are common on pig carcasses and present highly diverse genotypes and resistance phenotypes and genotypes.
\end{abstract}

INDEX TERMS: Escherichia coli, pig carcasses, pork, antibiotic resistance, PFGE, extended-spectrum $\beta$-lactamases (ESBL), resistance genes.

RESUMO.- [Genotipagem e resistência antimicrobiana de Escherichia coli em carcaças suínas.] 0 incremento de resistência frente aos antimicrobianos, observado em bactérias isoladas de humanos e animais, tem sido motivo de preocupação mundial e levado ao monitoramento dos perfis de resistência em bactérias patogênicas e comensais. 0 objetivo desse estudo foi avaliar o perfil de resistência em Escherichia coli isolada de carcaças suínas e descrever a ocorrência de alguns genes de resistência relevantes. Um total de 319 isolados de $E$. coli foi testado quanto à suscetibilidade frente a

\footnotetext{
${ }^{1}$ Received on October 7, 2016.

Accepted for publication on March 30, 2017.

${ }^{2}$ Departamento de Medicina Veterinária Preventiva, Faculdade de Veterinária, Universidade Federal do Rio Grande do Sul (UFRGS), Av. Bento Gonçalves 9090, Porto Alegre, RS 91540-000, Brazil. *Corresponding author: mcardoso@ufrgs.br

${ }^{3}$ Embrapa Suínos e Aves, Rodovia BR-153 Km 110, Concórdia, SC 89715899, Brazil.
}

diversos antimicrobianos. A presença de isolados produtores de $\beta$-lactamases (ESBL) de espectro estendido e $\beta$-lactamase induzível do tipo ampC foi também investigada. Dezoito cepas multirresistentes foram escolhidas para investigação de genes de resistência e caracterização por macro-restrição (PFGE). Os resultados demonstraram que a resistência a antimicrobianos está disseminada, pois $86,2 \%$ dos isolados de $E$. coli foram resistentes ao menos a um antimicrobiano e 71,5\% apresentaram perfil de multirresistência. Uma cepa de E. coli produtora de ESBL e nenhuma produtora de ampC induzível foram identificadas. Os genes strA ( $\mathrm{n}=15)$; flo $\mathrm{R}(\mathrm{n}=14) ; \operatorname{aac}(3)$ -IVa ( $\mathrm{n}=13) ;$ tet $\mathrm{B}(\mathrm{n}=13) ; \operatorname{sul} 2(\mathrm{n}=12) ;$ tet $\mathrm{A}(\mathrm{n}=11) ; \operatorname{aph}\left(3^{\prime}\right)$ Ia $(\mathrm{n}=8)$; sul3 $(\mathrm{n}=5)$ foram detectados por PCR. A análise de PFGE demonstrou que cepas de E. coli multirresistentes apresentaram similaridade inferior a $80 \%$ entre si. Concluiu-se que cepas multirresistentes de $E$. coli são frequentes em carcaças de suínos e apresentam uma alta diversidade genotípica, bem como de fenótipos e genes de resistência. 
TERMOS DE INDEXAÇÃO: Escherichia coli, carcaça suína, suínos, carne suína, resistência a antimicrobianos, PFGE, Beta-lactamases de espectro estendido, genes de resistência.

\section{INTRODUCTION}

Antimicrobial agents are essential for the treatment and control of bacterial infections. Therefore, the increasing antimicrobial resistance observed worldwide in bacteria isolated from humans and animals is a matter of extreme concern (FAO/WHO/OIE 2008). The selection of antimicrobial resistant bacteria in human medicine, mainly in hospital settings, directly affects the success of the treatment of critical patients (WHO 2001). Moreover, the intensification of animal production and greater reliance on antimicrobials to control infectious diseases and promote animal growth has emerged as an important factor in contributing to the selection of resistant bacteria in the community (Wyrsch et al. 2016). Resistant bacteria that colonize animals can be transmitted to humans via consumption and handling of contaminated food, direct contact with animals and even through the release of resistant bacteria into the environment (FAO/WHO/OIE 2008). As a consequence, antimicrobial resistance monitoring of pathogenic and commensal bacteria has been put in place in many countries (Brasil 2008, EFSA 2008, NARMS 2013). In a number of monitoring programs, commensal bacteria such as Escherichia coli and Enterococcus spp. have been adopted as indicators of the selection pressure exerted in the gut flora following antimicrobial administration (EFSA 2008).

Escherichia coli is a widespread and abundant bacteria which although capable of causing a wide range of gastrointestinal and extra-intestinal diseases, also forms part of the intestinal commensal microbiota of animals and humans. Therefore, it is considered a suitable bacteria for comparing the effects of selective pressure in all relevant populations and useful as an early alert system for tracking emerging resistant bacteria in livestock and their possible spread to animal-derived food (EFSA 2008). An additional concern is the transfer of antimicrobial resistance genes carried by commensal bacteria from the animal host to humans through the food chain or environment (FAO/WHO/OIE 2008). Thus, several resistance genes have been investigated in order to identify common resistance genes in bacteria from animals, food, the environment and humans (Krueger et al. 2011, Mendonça et al. 2016, Stange et al. 2016).

In Brazil, pig farming practices have increased in scale over the last decades (ABPA 2015), which has led to an increased use of antimicrobials of several classes, including some that are also used in the treatment of human diseases. Until now, although Salmonella antimicrobial resistance has often been reported in pig carcasses and pork products (Spricigo et al. 2008, Kich et al. 2011, Lopes et al. 2015), no monitoring program for antimicrobial resistance in zoonotic bacteria transmitted by pork has been conducted in Brazil. To the best of our knowledge, no data for antimicrobial resistance in commensal $E$. coli isolated from pig carcasses has been reported in Brazil. Therefore, the aim of this study was to evaluate the antimicrobial resistance profile in E. coli species and to assess the occurrence of a number of relevant resistance genes.

\section{MATERIALS AND METHODS}

Sample collection. Samples were collected in three commercial slaughterhouses, denoted A, B and C, which process 1,500 to 2,000 pigs per slaughter shift. According to the animal transportation form from each slaughterhouse batch, all pigs had received amoxicillin, ceftiofur, colistin, florfenicol and tiamulin on farm. Each slaughterhouse was visited twice and 14 carcasses were collected per visit. The first carcass was selected randomly and the following ones at 10 -minute intervals. A total of 84 carcasses were sampled. Sponges $\left(\mathrm{Nasco}^{\circledR}\right)$ were used to swab a $100 \mathrm{~cm}^{2}$ area from each ham, back, belly and jowl (Brasil 2007). Sponges taken from each carcass were pooled and put in sterile plastic bags containing $40 \mathrm{~mL}$ of buffered peptone water (BPW, Merck). Aliquots from each sample pool were streaked on violet red bile lactose agar (VRBA, Oxoid). After incubation $\left(35^{\circ} \mathrm{C} \pm 2 ; 24 \mathrm{~h}\right)$, three to five typical colonies were transferred to MacConkey agar plates and confirmed as Escherichia coli by biochemical tests (Quinn et al. 2011).

Antimicrobial susceptibility testing. Escherichia coli isolates were tested for antimicrobial susceptibility against eight different antimicrobial agents. The agar disc diffusion method was performed and evaluated according to the specifications of the Clinical and Laboratory Standards Institute (CLSI) documents VET01-S3 and M100S (CLSI 2013; CLSI 2016). The following discs (Oxoid) were used: ampicillin $(10 \mu \mathrm{g})$, cefotaxime $(30 \mu \mathrm{g})$, ceftazidime $(30 \mu \mathrm{g})$, florfenicol $(30 \mu \mathrm{g})$, gentamicin $(10 \mu \mathrm{g})$, nalidixic acid $(30 \mu \mathrm{g})$, sulfonamides $(300 \mu \mathrm{g})$ and tetracycline $(30 \mu \mathrm{g})$. Escherichia coli ATCC $^{\odot} 25922$ was used as a reference strain for quality control purposes. Isolates displaying resistance against cefotaxime and/or ceftazidime (extended-spectrum $\beta$-lactamase producers screening test) were subjected to ESBL-confirmatory testing by agar-diffusion test using disks containing cefotaxime or ceftazidime combined with clavulanic acid (CLSI 2016). Antimicrobial multi-resistance was defined as resistance to three or more classes of antimicrobial agents (CLSI 2016). Multi-resistant isolates were tested against ten additional antimicrobials: amikacin $(30 \mu \mathrm{g})$; cefoxitin $(30 \mu \mathrm{g})$; chloramphenicol $(30 \mu \mathrm{g})$; kanamycin $(30 \mu \mathrm{g})$; ertapenem $(10 \mu \mathrm{g})$; streptomycin $(10 \mu \mathrm{g})$; fosfomycin $(200 \mu \mathrm{g})$; netilmicin $(30 \mu \mathrm{g})$; nitrofurantoin $(300 \mu \mathrm{g})$; tobramycin $(10 \mu \mathrm{g})$; and trimethoprim $(5 \mu \mathrm{g})$. In multi-resistant strains displaying resistance to nalidixic acid, the minimum inhibitory concentration (MIC) for ciprofloxacin was screened by agar dilution following the recommendations of CLSI document M07-A9 (CLSI 2012). Strains presenting an MIC of $4 \mu \mathrm{g} \cdot \mathrm{mL}^{-1}$ ciprofloxacin were considered resistant (CLSI 2012). Cefoxitin resistant strains were investigated for inducible ampC- $\beta$-lactamase production by the phenotypic test using cefoxitin-EDTA disks as described by Black et al. (2005).

Antimicrobial resistance gene profiling and macro-restriction analysis. Eighteen multi-resistant E. coli strains, displaying profiles with $\geq 9$ antimicrobials, were chosen, independently of slaughterhouse origin, and investigated for the presence of several resistance genes previously reported in this genus. Genomic DNA for the PCR assay was prepared using the NucleoSpin $^{\odot}$ Tissue Kits (Macherey-Nagel). Genes coding resistance to aminoglycosides [strA, strB, aac(3)IVa, aph(3)Ia, ant(2)Ia], tetracyclines [tet $\mathrm{A}$, tet $\mathrm{B}$ and tet $\mathrm{G}$ ], sulfonamides (sul1, sul2, and sul3), and phenicols (catA1, floR) were investigated by PCR assay, using the primers listed in Table 1 .

DNA from the same eighteen multi-resistant strains was subjected to pulsed-field gel eletrophoresis (PFGE) analysis, following Pulse-Net procedures (http://www.cdc.gov/pulsenet/pathogens/pfge.html). The DNA samples were first digested with XbaI (Promega) and electrophoresis was performed on a 1\% agarose 
Table 1. Antimicrobial resistance genes investigated by PCR in Escherichia coli strains from pig carcasses: amplicons, primers and references

\begin{tabular}{|c|c|c|c|c|}
\hline Antimicrobial class & Resistance gene & Amplicon ( $p b)$ & Primers $\left(5^{\prime}-3^{\prime}\right)$ & Reference \\
\hline \multirow[t]{6}{*}{ Tetracycline } & tet $A$ & 953 & fw: GTAATTCTGAGCACTGT & Frech \& Schwarz 2000 \\
\hline & & & rv: CCTGGACAACATTGCTT & \\
\hline & tetB & 1169 & fw: ACGTTACTCGATGCCAT & Frech \& Schwarz 2000 \\
\hline & & & rv: AGCACTTGTCTCCTGTT & \\
\hline & tet $G$ & 1141 & fw: CTGCTGATCGTGGGTCT & Frech \& Schwarz 2000 \\
\hline & & & rv: TTGCGAATGGTCTGCGT & \\
\hline \multirow[t]{4}{*}{ Phenicol } & catA1 & 551 & fw: GGCATTTCAGTCAGTTG & Kikuvi et al. 2007 \\
\hline & & & rv: CATTAAGCATTCTGCCG & \\
\hline & floR & 1291 & fw: AGGGTTGATTCGTCATGACCA & Kadlec et al. 2007 \\
\hline & & & rv: CGGTTAGACGACTGGCGACT & \\
\hline \multirow[t]{10}{*}{ Aminoglycoside } & $\operatorname{aac}(3) I V a$ & 627 & fw: GTGTGCTGCTGGTCCACAGC & Jensen et al. 2006 \\
\hline & & & rv: AGTTGACCCAGGGCTGTCGC & \\
\hline & $\operatorname{aph}(3) I a$ & 669 & fw: AACGTCTTGCTCGAGGCCGCG & Jensen et al. 2006 \\
\hline & & & rv: GGCAAGATCCTGGTATCGGTCTGC & \\
\hline & $\operatorname{ant}(2) I a$ & 328 & fw: GGGCGCGTCATGGAGGAGTT & Jensen et al. 2006 \\
\hline & & & rv: TATCGCGACCTGAAAGCGGC & \\
\hline & strA & 645 & fw: TGACTGGTTGCCTGTCAGAGG & Kehrenberg \& Schwarz 2001 \\
\hline & & & rv: CCAGTTGTCTTCGGCGTTAGCA & \\
\hline & $s \operatorname{tr} B$ & 510 & fw: ATCGTCAAGGGATTGAAACC & Kikuvi et al. 2007 \\
\hline & & & rv: GGATCGTAGAACATATTGGC & \\
\hline \multirow[t]{5}{*}{ Sulfonamide } & sul1 & 839 & fw: TGGTGACGGTGTTCGGCATTCTGA & Grape et al. 2003 \\
\hline & & & rv: CTAGGCATGATCTAACCCTCGGTCT & \\
\hline & sul2 & 703 & fw: ACAGTTTCTCCGATGGAGGCC & Kehrenberg \& Schwarz 2001 \\
\hline & sul3 & 803 & rv: CTCGTGTGTGCGGATGAAGTC & Frane et al 2003 \\
\hline & suis & 003 & rv: ATCTGCAGCTAACCTAGGGCTTTGGA & Gidpe El di. 2003 \\
\hline
\end{tabular}

Table 2. Resistance frequency in Escherichia coli multi-resistant strains from pig carcasses sampled at three slaughterhouses $(A, B, C)$ located in Santa Catarina state, according to the antimicrobial classes

\begin{tabular}{|c|c|c|c|c|c|}
\hline & \multicolumn{5}{|c|}{ \% Resistance } \\
\hline & $\begin{array}{c}\mathrm{A} \\
(\mathrm{n}=89)\end{array}$ & $\begin{array}{c}B \\
(n=75)\end{array}$ & $\begin{array}{c}\mathrm{C} \\
(\mathrm{n}=64)\end{array}$ & $\begin{array}{c}\text { Total } \\
(n=228)\end{array}$ & P value \\
\hline Aminoglycosides & & & & & \\
\hline Gentamicin & 6.7 & 10.7 & 14.1 & 10.1 & 0.326 \\
\hline Tobramycin & 5.6 & 16.0 & 9.4 & 10.1 & 0.087 \\
\hline Amikacin & 0 & 1.3 & 0 & 0.4 & 0.359 \\
\hline Kanamycin & 30.3 & 38.7 & 26.6 & 32.0 & 0.285 \\
\hline Netilmicin & 2.2 & 5.3 & 7.8 & 4.8 & 0.276 \\
\hline Streptomycin & 68.5 & 70.7 & 56.2 & 65.8 & 0.159 \\
\hline Quinolone & & & & & \\
\hline $\begin{array}{l}\text { Nalidixic acid } \\
\boldsymbol{\beta} \text {-lactams }\end{array}$ & 79.8 & 76.0 & 70.3 & 75.9 & 0.402 \\
\hline Ampicillin & 82.02 & 84.0 & 76.5 & 81.1 & 0.516 \\
\hline Cefotaxime & 0 & 2.7 & 1.6 & 1.3 & 0.321 \\
\hline Cefoxitin & 0 & 1.3 & 3.1 & 1.3 & 0.531 \\
\hline Ceftazidime & 0 & 2.7 & 0 & 0.9 & 0.128 \\
\hline Phenicols & & & & & \\
\hline Florfenicol & 95.5 & 88.0 & 39.1 & 77.2 & $<0.001$ \\
\hline Chloramphenicol & 97.7 & 88.0 & 68.7 & 86.4 & $<0.001$ \\
\hline Tetracycline & & & & & \\
\hline Tetracycline & 96.6 & 97.3 & 100 & 97.8 & 0.352 \\
\hline Nitrofuran & & & & & \\
\hline Nitrofurantoin & 1.1 & 1.3 & 1.6 & 1.3 & 0.973 \\
\hline $\begin{array}{l}\text { Folate pathway } \\
\text { inhibitor/sulfonamide }\end{array}$ & & & & & \\
\hline Trimethoprim & 66.3 & 56.0 & 45.3 & 57.0 & 0.035 \\
\hline Sulfonamide & 88.8 & 77.3 & 89.1 & 85.1 & 0.071 \\
\hline
\end{tabular}

gel using 0.5X Tris-borate-EDTA buffer in a CHEF DR-II system (BioRad Laboratories) at $6 \mathrm{~V} / \mathrm{cm}$ for $21 \mathrm{~h}$ at $14^{\circ} \mathrm{C}$ with an initial switch time of $6.76 \mathrm{~s}$ and a final switch time of 35.38s. After PFGE, the gel was stained with ethidium bromide $(2 \mu \mathrm{g} / \mathrm{ml}$, Sigma $)$ and photographed under UV transillumination; image digitalization was processed using the Kodak 2200 system (Rochester). PFGE-banding patterns were compared using the Gel-Compar II software package (Applied Maths). Similarities between profiles were calculated using the Dice coefficient, with $1.7 \%$ optimization sets and tolerance. The patterns were clustered using the unweighted pair group method with arithmetic averages (UPGMA), and dendrograms were constructed.

Statistical analysis. The antimicrobial resistance frequencies of $E$. coli isolates from the different slaughterhouses were compared by chi-square test $\left(\chi^{2}\right)$ using the Stata Data Analysis and Statistical Software, version 12.0. A $P$ value of $<0.05$ was considered significant. For the purpose of this study, isolates with intermediate susceptibility were categorized as susceptible for statistical analysis.

\section{RESULTS}

Escherichia coli was detected in all sampled carcasses, resulting in 319 strains, which were tested for antimicrobial resistance. A total of 44 (13.8\%) were fully susceptible to the antimicrobials tested in this study, while 16 (5.0\%) and $31(9.7 \%)$ presented resistance to one and two antimicrobial classes, respectively. Single and double resistances were mostly to ampicillin $(21 / 47 ; 44.7 \%)$, tetracycline $(20 / 47 ; 42.5 \%)$, sulfonamide $(12 / 47 ; 25.2 \%)$ and nalidixic acid $(12 / 47 ; 25.2 \%)$. In slaughterhouse A, no E. coli strain was fully susceptible to the antimicrobials tested in this study, while in B and C this group of strains accounted for $20 \%$ of the total. Strains resistant to one or two antimicrobials represented $12.7 \%, 18.0 \%$ and $12.7 \%$ in slaughterhouses $\mathrm{A}, \mathrm{B}$ and $\mathrm{C}$ respectively.

A total of 228 (71.5\%) E. coli strains presented multi-resistance profiles, and were tested against ten additional antimicrobials. In line with the profiles presented by the 
multi-resistant strains (Table 2), tetracycline (97.8\%), chloramphenicol (86.4\%), sulfonamide (85.1\%) and ampicillin (81.1\%) were the most frequent resistances observed. All multi-resistant strains were susceptible to ertapenem and fosfomycin. The resistance frequency to antimicrobials was not significantly different among the isolates obtained from the three slaughterhouses, except for the class of phenicols, to which E. coli isolates from slaughterhouse C were significantly less resistant $(\mathrm{P}<0.001)$. Among the 172 multi-resistant $E$. coli strains displaying resistance to nalidixic acid, thirty (17.4\%) were also resistant to ciprofloxacin (Table 3). From the five strains displaying resistance to ceftazidime or cefotaxime, only one was positive in the confirmatory test for ESBL-production. Resistance to cefoxitin was also low $(3 / 228 ; 1.3 \%)$, and no strain presented a positive reaction in the inducible ampC- $\beta$-lactamase production test.

Table 3. Distribution of Escherichia coli strains resistant to nalidixic acid isolated from pig carcasses according to the Minimal Inhibitory Concentration (MIC) of ciprofloxacin

Total Number of isolates according to ciprofloxacin MIC $\left(\mu \mathrm{g} . \mathrm{mL}^{-1}\right)$ 0.0120 .0240 .0480 .0970 .1250 .190 .390 .781 .563 .124 .686 .259 .37

$\begin{array}{lllllllllll}172 & 2 & 2 & 3 & 3 & 78 & 43 & 9 & 1 & 1 & 30\end{array}$

The vertical line depict the breakpoint for resistance according to CLSI (2012).

The multi-resistant isolates presented profiles that conferred resistance to between three and 11 antimicrobials. From a total of 85 different resistance profiles identified, 50 were displayed by only one strain. The most frequent resistance profile in slaughterhouses A and B was [AmpChlFloNalStrSulTetTri], while in C it was [AmpChlSulTet]. Five genes were not detected in the 18 E. coli strains investigated for resistance genes by PCR: sul1, catA1, tetG, ant(2)
Ia and strB. Eight other resistance genes were detected at the following frequencies: strA ( $\mathrm{n}=15)$; flo $(\mathrm{n}=14) ; \operatorname{aac}(3)$ IVa $(\mathrm{n}=13) ;$ tet $\mathrm{B}(\mathrm{n}=13) ; \operatorname{sul} 2(\mathrm{n}=12) ;$ tet $\mathrm{A}(\mathrm{n}=11) ; \operatorname{aph}(3)$ Ia $(\mathrm{n}=8) ;$ sul3 $(\mathrm{n}=5)$. Six E. coli strains carried both tetA and tet $\mathrm{B}$ genes, and in seven strains the three aminoglycoside resistance genes investigated (strA, aac(3)Iva aph(3)Ia) were detected. The PFGE analysis of the 18 multi-resistant E. coli strains showed a high diversity of pulsotypes, and most strains presented similarity percentages of less than $80 \%$ among them (Fig.1). In slaughterhouses B and C, E. coli strains displaying indistinguishable pulsotypes, and similar phenotypic and genotypic resistance profiles, were detected. These strains were isolated from different carcasses belonging to the same slaughter batch.

\section{DISCUSSION}

The results presented here on E. coli isolated from pig carcasses show that resistance to antimicrobials is widespread, since of a total of 319 E. coli strains analyzed, $71.5 \%$ displayed multi-resistance profiles, while $86.2 \%$ were found to be resistant to at least one antimicrobial. The most likely origin of these resistant strains is the intestinal tract of the slaughtered pigs; therefore these bacteria may actually reflect the selection pressure that occurs following on-farm antimicrobial administration. Moreover, PFGE analysis of a group of multi-resistant $E$. coli revealed that they were genotypically diverse even among strains from the same slaughterhouse. Only four strains from B and three strains from $\mathrm{C}$, which were isolated from different carcasses belonging to common slaughter batches displayed same pulsotypes and resistance profiles. In these cases, cross-contamination during the dressing process may have been the cause of the dissemination of the multi-resistant strains. Therefore, a parallel selection of multiple $E$. coli groups belonging to the intestinal microbiota following exposure to antimicrobials

\section{Percent similarity}
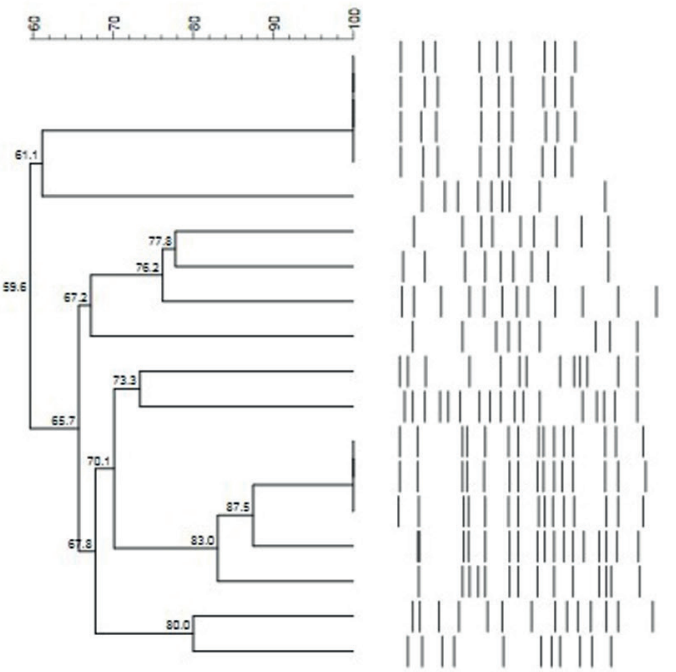

$\begin{array}{lll}\text { Slaughterhouse Batch } & \text { Phenotypic resistance profile } \\ \text { B } & 1 & \text { AmpChlFloKanNetStrSulTetTobTri } \\ \text { B } & 1 & \text { AmpChlFloKanNetStrSulTetTobTri } \\ \text { B } & 1 & \text { AmpChlFloGenKanNetSulStrTetTobTri } \\ \text { B } & 1 & \text { AmpChlFloKanStrSulTetTobTri } \\ \text { B } & 1 & \text { AmpChlFloKanStrSulTetTobTri } \\ \text { A } & 2 & \text { AmpChlFloGenNalStrSulTetTobTri } \\ \text { A } & 2 & \text { AmpChlFloGenKanNalStrSulTet } \\ \text { C } & 2 & \text { AmpCefChiCtxFloStrSulTetTri } \\ \text { A } & 2 & \text { ChlFloGenNalStrSulTetTobTri } \\ \text { B } & 2 & \text { AmpChlFloGenKanNalStrSulTetTri } \\ \text { B } & 2 & \text { AmpChlFloGenKanNalNetNitTetTobTri } \\ \text { C } & 1 & \text { ChiGenFloNalNetStrSulTetTob } \\ \text { C } & 1 & \text { ChiGenFloNalNetStrSulTetTob } \\ \text { C } & 1 & \text { ChiGenFloNalNetStrSulTetTob } \\ \text { B } & 2 & \text { AmpChlFloGenStrSulTetTobTri } \\ \text { B } & 2 & \text { ChlFloGenKanNalStrSulTetTob } \\ \text { C } & 2 & \text { AmpChlFloKanNalNetStrSulTetTob } \\ \text { A } & 1 & \text { AmpChlFloGenNalNetStrSulTetTobTri }\end{array}$

Genotypic resistance profile
floR, strA, aph(3)la, aac(3)IV, sul2, tetA, tetB
floR, strA, aph(3)la, aac(3)IV, sul2, tetA, tetB
floR, strA, aph(3)la, aac(3)IV, sul2, tetA, tetB
floR, strA, aph(3)la, aac(3)IV, sul2, tetA, tetB
floR, strA, aph(3)la, aac(3)IV, sul2, tetA, tetB
floR, strA, sul2, tetA
floR, strA, sul2, tetA
floR, strA, aac(3)IV, sul2, sul3, tetB
floR, sul2, tetA, tetB
aph(3)la, sul2, tetA
floR, tetA
strA, aac(3)IV, sul3, tetB
strA, aac(3)IV, sul3, tetB
strA, aac(3)IV, sul3, tetB
floR, strA, aac(3)IV, tetB
floR, strA, aph(3)la, aac(3)IV, sul3, tetA
floR, strA, aph(3)la, aac(3)IV, sul2, tetB
floR, strA, aac(3)IV, sul2, tetB

Fig.1. Macro restriction profiles and multi-resistant Escherichia coli isolated from pig carcasses from three slaughterhouses (A,B,C). Groups of related isolates ( $\geq 70 \%$ similarity) are marked with brackets. Amp $=$ ampicillin, Kan $=$ kanamycin, Cef $=$ cefoxitin, Chl $=$ chloramphenicol, Ctx = cefotaxime, Gen = gentamicin, Net = netilicin, Str = streptomycin, Flo = florfenicol, Nal = nalidixic acid, Sul = sulfonamide, Tet $=$ tetracycline, Tob = tobramycin, Tri $=$ trimethoprim. 
seems to be a more plausible scenario than the selection and transfer of resistant clones at the slaughterhouses. The selection pressure exerted by antimicrobial use is in turn reflected in the multi-resistance profiles, and in our study profiles of resistance of up to eleven antimicrobials were identified.

According to the animal transportation forms that were presented at the slaughterhouse for each pig batch, antimicrobials of the $\beta$-lactam class (amoxicillin and ceftiofur), florfenicol and tiamulin were administered to the animals on farm. The frequency of resistance to most antimicrobials did not differ greatly among $E$. coli strains isolated from slaughterhouse A, B and C. And ampicillin (81.1\%), sulfonamide (85.1\%) and tetracycline (97.8\%) figured among the antimicrobials with the highest percentage of resistant strains in all slaughterhouses. Resistance to ampicillin, tetracycline and sulfonamide is a common finding in monitoring program reports, and resistance frequencies between $37 \%$ and $57 \%$ in commensal $E$. coli isolated from pigs have been reported in countries of the European Union (EFSA 2008). Investigations conducted on E. coli isolated from pork also reported the highest frequency of resistance against these same three antimicrobials in Greece (68.6 to $78.4 \%$ ), the United States (15 to $51 \%$ ), Canada (12.2 to $31.7 \%$,) and Germany (21.7 to $28.3 \%$ ), demonstrating that this is a widespread resistance profile (Gousia et al. 2011, Kaesbohrer et al. 2012, Sheikh et al. 2012, Zhao et al. 2012), which is believed to be associated with the massive use of these antimicrobials on pig farms. Particularly, the administration of high doses of tetracycline, sulfonamides, macrolides and penicillin in combination or stand-alone treatments has been reported in high pork-producing countries such as the United States (Apley et al. 2012) and China (Krishnasamy et al. 2015). Even in countries of the European Union, where antimicrobial use for growth promotion was withdrawn, tetracycline and penicillin were still reported as the most used antimicrobials in animals in the year 2011 (Garcia-Migura et al. 2014).

Consequently, genes such as bla, tet and sul, which are involved in resistance to $\beta$-lactams, tetracycline and sulfonamide, respectively, feature among the most often reported in E. coli (Sunde et al. 1998, Abraham et al. 2014, Mendonça et al. 2016, Wyrsch et al. 2016). In most cases, multiple resistance genes of these groups form part of gene cassettes carried by transposons and plasmids, which enable the persistence of resistance to specific antimicrobials even after their withdrawal (Garcia-Migura et al. 2014). In fact, the 18 multi-resistant $E$. coli strains analyzed in our study carried genes tet $\mathrm{A}$ and tetB in addition to sul2 and sul3. The concomitant detection of sul2 and tetA occurred in nine multi-resistant $E$. coli strains; in seven other strains different combinations were observed (sul2 and tetB or sul3 and tetA/B). Since the location of the resistance genes was not investigated, we can only hypothesize the linkage of the aforementioned genes in one gene cassette or mobile element. The aforementioned genes are, in turn, frequently reported and highly prevalent in $E$. coli isolated from humans and the environment, demonstrating the dissemination of resistance genes and the circulation of resistant strains between the environment and human or animal hosts (Bryan et al. 2004, Tadesse et al. 2012, Yahiaoui et al. 2015, Stange et al. 2016).

In our study, chloramphenicol (86.4\%) and florfenicol (77.2\%) also feature among the antimicrobials to which high frequency of resistance is shown. Although chloramphenicol is prohibited for animal use in Brazil (Brasil 1999), florfenicol is frequently administered for the treatment of swine diseases (Barcellos et al. 2009). Whilst florfenicol is not administered to humans, E. coli strains resistant to this antimicrobial often carry the floR gene (Schwarz et al. 2006), which also confers resistance to chloramphenicol. In our study, concomitant resistance to these antimicrobials was observed in 176 (88.0\%) of 200 strains resistant to the group of phenicols. Moreover, in 14 of the 18 multi-resistant strains subjected to genotyping, resistance to both antimicrobials was observed and the floR was detected. In the four remaining strains, which presented this resistance phenotype without the detection of floR, other previously described mechanisms (Schwarz et al. 2006) could be involved. Therefore, we hypothesize that commensal $E$. coli in the pig gut may act as a reservoir of resistance genes such as floR, which confers cross-resistance to chloramphenicol. However, this drug still represents the therapy of choice for important human infections in certain geographic areas (WHO 2011).

In response to the increasing concern about resistance in bacteria, the World Health Organization (WHO) developed criteria to rank antimicrobials (WHO 2005). The antimicrobials were categorized according to the relative importance in human medicine as: critically important, highly important and important. According to the latest revised edition of the document (WHO 2011), tetracycline and sulfonamide are ranked as highly important, while penicillins, phenicols and aminoglycosides feature among the critically important, stressing the relevance of the resistance profiles detected in this study among $E$. coli strains obtained from pig carcasses.

Streptomycin resistance is a common finding in E. coli isolated from food animals and animal products (Kaesbohrer et al. 2012, Tadesse et al. 2012) and together with ampicillin, features among the resistance phenotypes that are often co-transferred with sulfonamide resistance in $E$. coli (Wu et al. 2010). In our study, 65.8\% of the multi-resistant E. coli strains were resistant to streptomycin and $32 \%$ to kanamycin. However, the tested strains presented much lower frequencies of resistance $(0.4$ to $10.1 \%)$ to the other tested aminoglycosides. Resistance to aminoglycoside is related to the enzymatic inactivation of the drug, and a plethora of $\mathrm{N}$-acetyltransferases, $\mathrm{O}$-phosphotransferases and O-nucleotidyltransferases involved in this inactivation have been described (Ramirez \& Tomalsky 2011). Among the resistance genes, strA-strB stand out as being widely disseminated in gram-negative bacteria isolated from humans, mammals and farmed fish (Sundin \& Bender 1996, Sunde et al. 1998, L'Abée-Lund \& Sorum 2001, Ramirez \& Tomalsky 2011, Abraham et al. 2014). In this study strA was the most frequently detected gene in the multi-resistant $E$. coli strains analyzed, followed by aac(3)IVa and aph(3)Ia. These genes code for enzymes of 0 -phosphotransferase (APH) 
and $\mathrm{N}$-acetyltransferase (AAC) types, which are able to modify streptomycin and kanamycin (APH) or gentamycin (AAC) (Shaw et al. 1993). The enzymatic profile in turn is in agreement with the most frequent resistance phenotypes detected in our study.

More recently, the critically important antimicrobials were further divided according to a prioritization based on the volume of antimicrobial usage, revealing that transmission of resistant bacteria from non-human sources is already occurring (WHO 2011). The analysis resulted in four groups of drugs of highest priority among the critically important antimicrobials: fluoroquinolones, third and fourth generation cephalosporins, macrolides and glycopeptides. The first two groups are active against enterobacteria and have been included in monitoring programs that use E. coli as indicator of antimicrobial exposure (EFSA 2008, NARMS 2013), and were also investigated in our study.

Quinolone resistance is most often associated with mutations in the gene coding for DNA gyrase and topoisomerase IV in E. coli, although other mechanisms may also be involved (Karczmarczyk et al. 2011). The mutations facilitate the selection of mutants resistant to high levels of quinolones which may also present an enhancement in MICs of fluoroquinolones such as ciprofloxacin (Jacoby 2005). In our study, nalidixic acid resistance was highly frequent, being detected in $75.9 \%$ of the $E$. coli strains. When the resistant strains were tested against ciprofloxacin, $17.4 \%$ presented an MIC of $\geq 4 \mu$ g. $\mathrm{mL}^{-1}$, which is the breakpoint for clinical resistance (CLSI 2012). Besides these already resistant strains, $95.9 \%$ presented MIC values greater than $0.064 \mu \mathrm{g} . \mathrm{mL}^{-1}$, which is the concentration breakpoint of strains already showing a degree of resistance mutation (EUCAST 2016). In this sense, strains able to survive in higher concentrations of ciprofloxacin are more likely to undergo additional mutations and become fully resistant to fluoroquinolones (Jacoby 2005). Therefore, the MIC profiles identified in the E. coli strains from pig carcasses in this study suggest that more ciprofloxacin resistant strains may emerge in the future.

Beta-lactam antimicrobials are still the most frequently used antibiotics in the treatment of bacterial infections. However, continuous exposure to antimicrobials of this class has contributed to the emergence and selection of resistant bacteria carrying genes coding for $\beta$-lactamases (Shaikh et al. 2015). Extended-spectrum $\beta$-lactamases (ESBLs), which confer resistance to monobactams and all $\beta$-lactams, except those combined with $\beta$-lactamase inhibitors, have gained importance worldwide. In our study, only $1.3 \%$ and $0.9 \%$ of the strains analyzed presented resistance to ceftazidime or cefotaxime, which are used to screen for ESBL producers. Among the already low numbers of resistant strains, only one has been confirmed to be ESBL producer by the phenotypic test. In agreement with the group of $E$. coli strains analyzed here, the frequencies reported for ESBL producers in animals have generally been below 1\% (EFSA 2008). Nonetheless, ceftiofur, which belongs to the group of third generation cephalosporins, is frequently used in pig farms in Brazil and might exert a selection pressure on the microbiome, highlighting the importance of constant monitoring for resistance development in pathogens and commensal bacteria.

More recently, inducible ampC- $\beta$-lactamases, which possess broad-spectrum cephalosporinase action in addition to being capable of hydrolyzing penicillins and $\beta$-lactamase inhibitor- $\beta$-lactam combinations, have been detected in $E$. coli. Due to the clinical importance of these drugs and the location of the resistance gene on plasmids, screening and confirmation tests have been developed (Black et al. 2005). Of these, we used the cefoxitin disk diffusion test for screening purposes, while the identification of resistant strains was confirmed using cefoxitin-EDTA disks. No inducible ampC- $\beta$-lactamase producer was found among the E. coli strains isolated from pig carcasses in this study. This result, together with the absence of strains resistant to ertapenem and fosfomycin, is encouraging, since these drugs are highly important for the treatment of humans. Moreover, their administration should be avoided in animals.

Although the relationship between the withdrawal of a given antimicrobial from animal use and the decrease in resistance to it in humans is not straightforward, evidence indicates that the single most important driver for the emergence and increased resistance in the microbiome is the use of antimicrobial agents in humans and animals (Aarestrup 2015). Therefore, the high frequency of multi-resistant $E$. coli strains in pig carcasses demonstrates that these bacteria are subjected to permanent contact with a number of classes of antimicrobials. In particular, the use of oral treatment for extended periods of time of whole animal herds, adopted for practical reasons in animal husbandry, is recognized as exerting high selection pressure on bacterial populations (Ungemach et al. 2006). Therefore, the prudent and responsible use of antimicrobials in animals is of utmost importance in the control of antimicrobial resistance. Measures, including the use of antimicrobials only when necessary, according to instructions, after appropriate disease diagnosis, and, when possible, following resistance tests, form the basis for the prudent use of antimicrobials. The results of this study indicate that antimicrobial resistance should be prioritized in the discussion concerning antimicrobial administration in swine production.

\section{CONCLUSIONS}

Escherichia coli isolated from pig carcasses are highly resistant to antimicrobials belonging to the class of $\beta$-lactams, tetracyclines, sulfonamides, phenicols, aminoglycosides and quinolones; moreover, they frequently display multi-resistance profiles.

Resistance to antimicrobials of high priority in human medicine, such as third and fourth generation cephalosporins, monobactams and fosfomycin, is rare or even absent. E. coli strains resistant to fluoroquinolones are, however, found in pig carcasses.

Antimicrobial resistant E. coli strains present highly diverse resistance phenotypes, genotypes and pulsotypes, indicating that they most likely come with each animal entering the slaughterhouse rather than being resident resistant clones transferred by cross contamination. 


\section{REFERENCES}

Aarestrup F.M. 2015. The livestock reservoir for antimicrobial resistance: a personal view on changing patterns of risks, effects of interventions and the way forward. Philos. Trans. R. Soc. Lond. B, Biol. Sci. 370:20140085.

ABPA 2015. Relatório Anual de Atividades de 2014, Associação Brasileira de Proteína Animal, p.1-245.

Abraham S., Trott D.J., Jordan D., Gordon D.M., Groves M.D., Fairbrother J.M., Smith J.M., Zhang R. \& Chapman T.A. 2014. Phylogenetic and molecular insights into the evolution of multidrug-resistant porcine enterotoxigenic Escherichia coli in Australia. Int. J. Antimicrob. Agents 44(2):105-111.

Apley M.D., Bush E.J., Morrison R.B., Singer R.S. \& Snelson H. 2012. Use estimates of in-feed antimicrobials in swine production in the United States. Foodborne Pathog. Dis. 9(3):272-279.

Barcellos D.E.S.N., Marques B., Mores T., Coelho C. \& Borowski S. 2009. Aspectos práticos sobre o uso de antimicrobianos em suinocultura. Acta Sci. Vet. 37:s151-s155.

Black J.A., Moland E.S. \& Thomson K.S. 2005. AmpC disk test for detection of plasmid-mediated AmpC B-lactamases in Enterobacteriaceae lacking chromosomal AmpC B-lactamases. J. Clin. Microbiol. 43:3110-3113.

Brasil 1999. Instrução Normativa SDA/MAA 42/1999. Plano nacional de controle de resíduos em produtos de origem animal.

Brasil 2007. Circular no 130/2007/CGPE/DIPOA. Exportações de carne suína para os estados membros da União Europeia.

Brasil 2008. Relatório do Monitoramento da prevalência e do perfil de suscetibilidade aos antimicrobianos em enterococcus e salmonelas isolados de carcaças de frango congeladas comercializadas no Brasil. Programa nacional de monitoramento da prevalência e da resistência bacteriana em frango, PREBAF.

Bryan A., Shapir N. \& Sadowsky M.J. 2004. Frequency and distribution of tetracycline resistance genes in genetically diverse, nonselected, and nonclinical Escherichia coli strains isolated from diverse human and animal sources. Appl. Environ. Microbiol. 70(4):2503-2507.

CLSI 2012. Methods for Dilution Antimicrobial Susceptibility Tests for Bacteria that Grow Aerobically, approved standard. 9th ed. Clinical and Laboratory Standards Institute, Wayne.

CLSI 2013. Performance Standards for Antimicrobial Disk and Dilution Susceptibility Tests for Bacteria Isolated From Animals, approved standard. 4th ed. Clinical and Laboratory Standards Institute, Wayne.

CLSI 2016. Performance Standards for Antimicrobial Susceptibility Testing. 26th ed. Clinical and Laboratory Standards Institute, Wayne.

EFSA 2008. Report from the task force on zoonoses data collection including guidance for harmonized monitoring and reporting of antimicrobial resistance in commensal Escherichia coli and Enterococcus spp. from food animals, European Food Safety Authority. EFSA J. 141:1-44.

EUCAST 2016. MIC distributions and ECOFFs. European Society of Clinical Microbiology and Infectious Diseases, European Committee on Antimicrobial Susceptibility Testing.

FAO/WHO/OIE 2008. Expert meeting on critically important antimicrobials. Report of the FAO/WHO/OIE Expert Meeting. FAO Headquarters, Rome, Italy. 67p.

Frech G. \& Schwarz S. 2000. Molecular analysis of tetracycline resistance in Salmonella enterica subsp. enterica serovars Typhimurium, Enteritidis, Dublin, Choleraesuis, Hadar and Saintpaul: construction and application of specific gene probes. J. Appl. Microbiol. 89:633-641.

Garcia-Migura L., Hendriksen R.S., Fraile L. \& Aarestrup F.M. 2014. Antimicrobial resistance of zoonotic and commensal bacteria in Europe: The missing link between consumption and resistance in veterinary medicine. Vet. Microbiol. 170:1-9.

Gousia P., Economou V., Sakkas H., Leveidiotou S. \& Papadopoulou C. 2011. Antimicrobial resistance of major foodborne pathogens from major meat products. Foodborne Pathog. Dis. 8(1):27-38.

Grape M., Sundström L. \& Kronvall G. 2003. Sulphonamide resistance gene sul3 found in Escherichia coli isolates from human sources. J. Antimicrob. Chemother. 52(6):1022-1024.
Jacoby G. 2005. Mechanisms of resistance to quinolones. Clin. Infect. Dis. 41:120-126.

Jensen V.F., Jakobsen L. \& Emborg H.D. 2006. Correlation between apramycin and gentamicin use in pigs and an increasing reservoir of gentamicin-resistant Escherichia coli. J. Antimicrob. Chemother. 58:101-107.

Kadlec K., Kehrenberg C. \& Schwarz S. 2007. Efflux-mediated resistance to florfenicol and/or chloramphenicol in Bordetella bronchiseptica: identification of a novel chloramphenicol exporter. J. Antimicrob. Chemother. 59:191-196

Kaesbohrer A., Schroeter A., Tenhagen B.A., Alt K., Gerra B. \& Appel B. 2012. Emerging antimicrobial resistance in commensal Escherichia coli with public health relevance. Zoonoses Public Health. 59(2):158165.

Karczmarczyk M., Martins M., Quinn T., Leonard N. \& Fanning S. 2011. Mechanisms of fluoroquinolone resistance in Escherichia coli isolates from food-producing animals. Appl. Environ. Microbiol. 77:7113-20.

Kehrenberg C. \& Schwarz S. 2001. Occurrence and linkage of genes coding for resistance to sulfonamides, streptomycin and chloramphenicol in bacteria of the genera Pasteurella and Mannheimia. FEMS Microbiol. Lett. 205:283-290.

Kich J.D., Coldebella A., Morés N., Nogueira M.G., Cardoso M., Fratamico P.M., Call J.E., Fedorka-Cray P. \& Luchansky J.B. 2011. Prevalence, distribution, and molecular characterization of Salmonella recovered from swine finishing herds and a slaughter facility in Santa Catarina, Brazil. Int. J. Food Microbiol. 151(3):307-131.

Kikuvi G.M., Schwarz S., Ombui J.N., Mitema E.S. \& Kehrenberg C. 2007. Streptomycin and chloramphenicol resistance genes in Escherichia coli isolates from cattle, pigs, and chicken in Kenya. Microb. Drug Resist. 13:62-68.

Krishnasamy V., Otte J. \& Silbergeld E. 2015. Antimicrobial use in Chinese swine and broiler poultry production. Antimicrob. Resist. Infect. Control $4: 17$

Krueger A.L., Folster J., Medalla F., Joyce K., Perri M.B., Johnson L., Zervos M., Whichard J.M. \& Barzilay E.J. 2011. Commensal Escherichia coli isolate resistant to eight classes of antimicrobial agents in the United States. Foodborne Pathog. Dis. 8:329-332.

L'Abée-Lund T.M. \& Sorum H. 2001. Class 1 integrons mediate antibiotic resistance in the fish pathogen Aeromonas salmonicida worldwide. Microb. Drug Resist. 7:263-272.

Lopes G.V., Pissetti C., Pellegrini D.C.P., Silva L.E. \& Cardoso M. 2015. Resistance phenotypes and genotypes of Salmonella enterica subsp. enterica isolates from feed, pigs, and carcasses in Brazil. J. Food Prot. 78:407-413.

Mendonça N., Figueiredo R., Mendes C., Card R., Anjum M. \& Silva G. 2016. Microarray evaluation of antimicrobial resistance and virulence of Escherichia coli isolates from Portuguese poultry. Antibiotics 5:4.

NARMS 2013. NARMS integrated report: 2012-2013. The national antimicrobial resistance monitoring system: enteric bacteria. 34p.

Quinn P.J., Markey B.K., Leonard F.C., Fitzpatrick E.S., Fanning S. \& Hartigan P.J. 2011. Veterinary Microbiology and Microbial Disease. 2nd ed. Wiley-Blackwell, Iowa. 1231p.

Ramirez M.S. \& Tomalsky M.E. 2011. Aminoglycoside modifying enzymes. Drug Resist. Updat. 13(6):151-171.

Schwarz S., Cloeckaert A. \& Roberts M.C. 2006. Mechanisms and spread of bacterial resistance to antimicrobial agents, p.73-98. In: F.M. Aarestrup (Ed.), Antimicrobial resistance in bacteria of animal origin. ASM Press, Washington, D.C.

Shaikh S., Fatima J., Shakil S., Rizvi S.M.D. \& Kamal M.A. 2015. Antibiotic resistance and extended spectrum beta-lactamases: Types, epidemiology and treatment. Saudi J. Biol. Sci. 22(1):90-101.

Shaw K.J., Rather P.N., Hare R.S. \& Miller G.H. 1993. Molecular genetics of antimicrobial resistance genes and familial relationships of the aminoglycoside-modifying enzymes. Microbiol. Rev. 51(1):138-163.

Sheikh A.A., Checkley S., Avery B., Chalmers G., Bohaychuk V., Boerlin P., Reid-Smith R. \& Aslam M. 2012. Antimicrobial resistance and resistance genes in Escherichia coli isolated from retail meat purchased in Alberta, Canada. Foodborne Pathog. Dis. 9(7):625-631. 
Spricigo D.A., Matsumoto S.R., Espindola M.L., Vaz E.K. \& Ferraz S.M. 2008. Prevalência e perfil de resistência a antimicrobianos de sorovares de Salmonella isolados de lingüiças suínas tipo frescal em Lages, SC. Arq. Bras. Med. Vet. Zootec. 60(2):517-520.

Stange C., Sidhu J.P.S., Tiehm A. \& Toze S. 2016. Antibiotic resistance and virulence genes in coliform water isolates. Int. J. Hyg. Environ. Health 219(8):823-831.

Sunde M., Fossum K., Solberg A. \& Sørum H. 1998. Antibiotic resistance in Escherichia coli of the normal intestinal flora of swine. Microb. Drug Resist. 4:289-299.

Sundin G.W. \& Bender C.L. 1996. Dissemination of the strA-strB streptomycin-resistance genes among commensal and pathogenic bacteria from humans, animals, and plants. Mol. Ecol. 5:133-143.

Tadesse D., Zhao S., Tong E., Ayers S., Singh A., Bartholomew M. \& McDermott P. 2012. Antimicrobial drug resistance in Escherichia coli from humans and food animals, United States, 1950-2002. Emerg. Infect. Dis. 18(5):741-749.

Ungemach F.R., Müller-Bahrdt D. \& Abraham G. 2006. Guidelines for prudent use of antimicrobial and their implications on antibiotic usage in veterinary medicine. Int. J. Med. Microbial. 296(41):33-38.

WHO 2001. WHO Global Strategy for Containment of Antimicrobial Resistance. World Health Organization, Geneva. 105p.
WHO 2005. Critically Important Antibacterial Agents for Human Medicine for Risk Management Strategies of Non-Human Use. Report of a WHO working group consultation, Canberra, Australia, 15-18 February 2005. World Health Organization, Geneva.

WHO 2011. Critically Important Antimicrobials for Human Medicine. 3rd revision. World Health Organization, Geneva. 38p.

Wu S., Dalsgaard A., Hammerum A.M., Porsbo L.J. \& Jensen L.B. 2010. Prevalence and characterization of plasmids carrying sulfonamide resistance genes among Escherichia coli from pigs, pig carcasses and human. Acta Vet. Scand. 52:30-47.

Wyrsch E.R., Roy Chowdhury P., Chapman T.A., Charles I.G., Hammond J.M. \& Djordjevic S.P. 2016. Genomic microbial epidemiology is needed to comprehend the global problem of antibiotic resistance and to improve pathogen diagnosis. Front. Microbiol. 7:843.

Yahiaoui M., Robin F., Bakour R., Hamidi M., Bonnet R. \& Messai Y. 2015. Antibiotic resistance, virulence, and genetic background of community-acquired uropathogenic Escherichia coli from Algeria. Microb. Drug Resist. 21(5):516-526.

Zhao S., Blickenstaff K., Bodeis-Jones S., Gaines S.A., Tong E. \& McDermott P.F. 2012. Comparison of the prevalences and antimicrobial resistances of Escherichia coli isolates from different retail meats in the United States, 2002 to 2008. Appl. Environ. Microbiol. 78:1701-1707. 